\title{
Principles of Sustainable Development of Businesses on the Adaptive Lifecycle Dimension of Connectedness
}

By

${ }^{1}$ K Sriram, Prof. L.S. Ganesh and Prof. R. Madhumathi

\begin{abstract}
The Panarchy model of ecological systems and analogically business systems identifies 3 dimensions of sustainability over the adaptive life cycle of a system. Principles on the second dimension of the Panarchy model, namely connectedness, are discussed in this paper. These principles relate to processes, networks and controls of ecological systems and analogically business systems. Examples of operation of these principles in the business context are given.
\end{abstract}

Key Words: sustainable, development, systems, morphology, analogy, ecology, business, connectedness

\section{Introduction}

Sustainable Development (SD) can be defined as "Development that meets the needs of the present, without compromising the ability of future generations to meet their own needs" (WCED, 1987). SD of business involves preservation and enhancement of the stock of resources - financial, ecological, societal, human, physical and others - on which businesses depend upon quantitatively and qualitatively, in the short- and long-run (Stiglitz et al, 2009). SD of business also involves reduction of waste and risks in the socio-ecological context (Hanson et al, 2010). This must be done, while meeting the materialistic needs of society at appropriate prices, quality and timeframes. Unless SD of business is measured on the triple bottom line of people (society), planet (ecology) and profit/prosperity (economy), it cannot be achieved. (Elkington, 1998).

The following issues with regard to sustainable Development of Business were discussed in Self Reference (2013) 
a. The three dimensions, potential, connectedness and resilience, characterising the sustainability over the adaptive lifecycle in the Panarchy Model

b. The gaps in the existing literature on the principles of SD of business. This include the lack of principles at a higher level of abstraction and lack of cohesive and complete set uf principles.

c. The process of analogical reasoning in general, including its strengths and limitations

d.Suitability of ecological systems in the context of SD of business

e. The overarching principle of SD of business, namely "Manage with life cycle orientation"

In this paper principles of SD of business on the dimension of 'Connectedness', is derived and inferred in detail using the same process as in Selfreference, 2013. The source context for the same is sustainability of ecological systems and the target context is the Sustainable Development (SD) of business. These are discussed at 2 levels, namely socio-economic system (SE), and machine/technology system (MT).

\section{The Dimension of Connectedness}

Ecological systems consists of 3 dimensions that contribute to its sustainability over the self adaptive life cycle, as in Panarchy model (Gunderson and Holling, 2002). Business systems also seem to possess these 3 dimensions contributing to its sustainability (Simmie and Martin, 2010). Principles of SD of business related to the dimensions of connectedness or internal relationships are discussed in detail in this paper.

'Connectedness' can be loosely defined as internal relationships. In ecological systems 'connectedness' refers tothe extent of diffusion or connectedness of internal elements (variables) through their connections and relationships (processes). These could include the connectedness between and among species and non-living matter in ecological systems. Low connectedness in the system is an indication of diffused elements that are loosely coupled. Hence, the behaviour of the system is dominated more by outward relations and affected largely by outside variability. High connectedness means tight coupling among the aggregated elements, with the system's behaviour being dominated more by inward relationships among the aggregate elements. The high connectedness enables mediation or control of the influence of variability of external elements (e.g. temperature regulation in warm blooded animals, which involves five different physiological mechanisms).

In a business context, 'connectedness' refers to the internal relationships of actors and components (traded and un-traded dependencies between stakeholders, units within and outside the organization, local networks of trust, formal and informal associations, social networks, knowledge spillovers, patterns of mobility within and from outside the network). This is similar to the concept of connectedness in ecosystems, but also includes the idea of actors (human stakeholders with foresight and conscious choice). Clearly, connectedness is one of the key dimensions that leads to sustainability of ecological systems and analogously business systems. 


\subsection{Principles for sd of business related to 'connectedness'}

In this section, principles of SD of business closely related to the dimension of connectedness or internal relationships are discussed. The process of analogical reasoning from the source context of sustainability of ecological system to the target context of SD of business system is used. This is appropriately supplemented with business literature and other methods such as systems thinking and morphological analysis.

The mapping in the analogy need not always be one to one. It may be many to one, one to many and many to many. The principles of SD of business, on the dimension of connectedness, discussed here, has the following structure:

a) Based on observations from nature, a principle and its sub-principles of sustainability related to connectedness are abstracted.

b) This is applied to a business context in general, and SD of business context in particular. Sub-principles, strategic perspectives and strategic initiatives supporting the same are also inferred.

c) This discussion under each principle is summarized at the end in a table.

d) After this, examples of applications of the principle in current business practice are provided.

The principles of SD discussed in this paper are applicable at all the levels of the business system: (a) product level, (b) process and project level, (c) unit or department level, (d) business/organizational level, and (e) socio-economic systems level (provincial, national, regional and global). Each principle is typically relevant to all aspects of the triple bottom line. The principles are applicable at all geographies and vertical industries. All the principles, individually and collectively, must be noted as necessary conditions to ensure SD of business systems related to the dimension of connectedness. The principles related to business SE and MT systems are discussed separately.

The key properties related to connectedness concern the processes, networks and controls in ecological systems and hence analogically with business systems. Businesses should learn from nature to have appropriate and tailored mechanisms of connectedness that will lead to SD.

The principles related to connectedness, discussed in this paper are:

C1. Respect and Improve Processing Power

C2. Ensure Synergy through networking

C3. Adopt appropriate controls.

\section{Principle C1: Respect and Improve Processing Power}

Processing power is the limit of the system in handling its throughput. It is determined more by the connectivity between the nodes of the system than the number of nodes (e.g., the human brain) and hence is a key property related to Connectedness.

In the context of sustainability of ecosystems, inputs far in excess of a system's capability to process them (processing power) are bad for the system. For instance, 
nitrogen is crucial in nature, since plants, the primary producers, require nitrogen for photo synthesis. Although nitrogen is abundant in our atmosphere, it cannot be used in this form by plants. It is converted and fixed into the soil in usable forms naturally and in complex ways, by nitrogen fixing bacteria such as Rhizobium and plants such as legumes, other than by lightning strikes. Thus, in the use of organic agricultural methods, nitrogen availability to the plants is limited by this processing power in nature (Moir, 2011). Similarly, marshlands process nitrogen coming from streams into nitrites $\left(\mathrm{NO}_{3}\right)$. Studies have indicated that this process of nitrification has limits on the concentration of nitrogen coming into the marsh system. When the concentration in the stream is above the limits due to and including excess fertilizer wash off, the processing power limit of the marsh is exceeded, and the nitrogen in the water coming into the marshland is passed on to the oceans without complete nitrification by marsh. This could adversely affect the ocean ecosystem, if it is beyond a reasonable threshold (Drake et al, 2009). Other examples of bad effects of excess input in ecosystems include excess rain in a forest or excess carbon dioxide in the atmosphere. Ecosystems, left to themselves, curb excesses from within and across time through intriguing systemic processes (Benyus, 1997).

Conventional business practices respect financial processing power, in terms of cash flows and fund flows. Such practices need to be extended to social and ecological sustainability. Considering an economy and its interactions with ecosystems, there are limits to which its throughput can be tolerated by its corresponding natural environment. This is based on the limits of bio-physics and thermodynamics (Daly and Cobb, 1989). Some researchers have observed that these natural limits have been crossed by the levels of economic activity and lifestyles in the $20^{\text {th }}$ century, especially in the past 30 years (Meadows and Meadows 1992; McNeil, 2000; Meadows and Meadows, 2004). The 'Limits to Growth' theory points to the possibility of sudden and irreversible collapse of society, business SE and MT systems, if we continue to transgress the ecosystems' limits (Meadows \& Meadows 1992). Hence, there is a need to reduce industrial and business 'metabolism' to a level below the processing capacity of the relevant ecosystem, through material and energy flow analysis in an economy (Lovains et al., 1999), and improve processing power of the relevant ecosystem.

Applied in an individual business SE context, lack of attention to this principle will result in wastage of natural resources, like huge work-in-progress. Further, when the amount of an input into a system is more than its processing power, there is a possibility of the system crashing - as in the case of data overload in a computer. Such information overload, in excess of the processing capacity of an individual or a business, leads to communication gaps and poor business decisions. Such overload can be tackled by applying pre-filtering of information to avoid information overload through tools, techniques and processes for easier comprehension by managers. Hence, there is a need to increase the quality and functionality of throughput apart from the quantity alone (Benyus, 1997). Further, there is a need to apply 'lean thinking' concepts, first proposed by Ohno (1998) in Toyota. This concept is further explained by Womack and Jones (1996), in a book with the same title. 
In the case of business MT systems, a generation surplus of approximately 3,000 MW that was fed into the power grid led to the great blackout of North-East USA and Canada on August 14, 2003. This is an example of failure of a business MT system due to not adhering to the sub-principle of respecting the processing power (Lerner, 2003).

A few examples of the application of the principle of Respect and Improve Processing Power in the context of SD, are given after Table 1. The analogy between ecosystems and business systems, with reference to the principle of Respect and Improve Processing Power is summarized in Table 1. The table indicates that both business SE and MT systems should reduce their 'metabolism' to below their relevant ecosystems' processing power.

Table 1: Analogy for Principle C1: Respect and Improve Processing Power

\section{Sub-Principles for Ecosystems Sustainability:}

a) The connectivity between nodes, rather than the number of nodes, affects processing power.

b) Ecosystems curb excesses from within and across time through intriguing systemic processes.

\section{Sub-Principles for SD of Business:}

\section{Business SE Systems}

a) Reduce business 'metabolism' to below the processing capacity of the relevant ecosystem.

b) Improve the processing power of the relevant ecosystem.

c) Increase the quality and functionality of throughput apart from the quantity alone.

\section{Business MT Systems}

a) Apply pre-filtering of information to avoid information overload.

b) Apply 'lean thinking' concepts.

While the sub-principle of Lean Thinking, (b) of MT systems in table 1, a popular systems approach sub-principle, has been often quoted in manufacturing and processing contexts, rarely has it found mention in literature dealing with SD of business. SouthWest Airlines is a good example of the application of this sub principle. Typically, most airlines follow a 'hub and spoke system', in which large aircraft fly to major destinations (hubs), and smaller aircraft fly to less traveled routes from the hubs. Invariably, this leads to a large stock of passenger overload in the system at major hubs. This results in excessive commuting time for passengers and perhaps high energy consumption per passenger-km. However, South-West Airlines shuttles smaller and more aircraft to less traveled routes on a point-to-point basis, and this has led to better customer satisfaction due to lower commuting time (Lovins et al, 1999). This practice is also associated with a lowering of net energy (including aviation fuel) consumption.

The partnership between the Swiss Federal Railways and the car sharing company, Mobility, which commenced in 1997, is an interesting example of this principle. Car sharing is an innovative concept for those who do not want to own cars. Mobility parks cars at pre-specified places for pre-specified journeys and times. Mobility clients can car pool and at the same time request for a car that meets their requirements. This 
partnership allows consumers to get dedicated transport options from any Swiss Railway station for attractive prices. It also reduces the ecological impacts of such travel by as much as $50 \%$ on energy spent. This further leads to higher customer loyalty for the two companies involved (WBCSD, 2000). This is a good illustration of the sub-principles of (a), (c), in SE systems in table 1.

Cook Composites and Polymers (CCP) is a company involved in the resins and polymer business in the US. This company had a perpetual problem of flooding in Houston, due to its impervious paving and outdated storm water drainage facility. The company decided to use a wetland to substitute storm water drainage, due to its better processing power of storm water. This has been achieved with lower financial, social and ecological costs (WBCSD, 2010). This is an example of the sub-principle of (b) of SE systems table 1.

The energy processing power to increase the speed has a limit on the maximum speed beyond which the energy required for any speed gain increases drastically. However, by understanding swimming of ducks at speeds reaching over 13 lengths of duck per second, speed boat designers are perfecting hydroplaning technology to overcome the energy processing power of conventional boats (Fish, 2006). This is another example of the sub-principle (c) in SE systems in table 1.

From this principle based on a process perspective of sustainability, we move to the next principle based on networks perspective.

\section{Principle C2: Ensure Synergy through Networking}

Synergy is characterized by phenomena in which the 'whole (ecosystems) is more than the sum of its 'parts' (species and non-living matter) (Lovelock, 1979; Leveque, 2003). This is an appropriate property of Connectedness (networking), when the higher purpose is synergy.

A key feature of ecosystems in the context of sustainability is that symbionts or keystones have higher odds of flourishing compared to hyper parasites or hub-landlords (e.g., smallpox) (Benyus, 1997). An integrated existence with a tendency to partner, associate, establish links, live inside or with one another and cooperate (i.e. networking in nature), is exhibited by many living organisms. Further, an ecosystem is also linked to or networked with other ecosystems. For example, terrestrial ecosystems are linked to marine ecosystems through the water, carbon and other cycles. In ecosystems, even competing animals, typically of the same species, often minimize or even avoid interfering with their competitors spatially and temporally. This behavior is known to minimize waste of energy (friction) involved in competition (Benyus, 1997). Such integrated existence through networking, with minimization of friction, is a necessary condition for synergy. 
Through interactions in a symbiotic system, and through the effects of the natural environment in which various processes occur, the new, special and heterogeneous become the new, general and homogenous (Jacobs, 2000). Everything has a living, flowing connection with everything else directly or indirectly, i.e. is networked completely, and there are no isolated entities in ecosystems. An example of this principle in ecosystems is found in coral reefs, where several organisms live symbiotically and synergetically in the structure provided by coral polyps in an interconnected manner (Benyus, 1997). Similarly, in a rain forest, several species live symbiotically, networked with one another. In such an ecosystem, co-evolution takes place, individuals do not evolve independently but collectively within the system, and the fitness of one species clearly depends upon the fitness of another (Mitleton-Kelly, 2003).

The proximate environment of a business consists of all the companies, organizations or groups of people that directly or indirectly affect and are affected by it. These include suppliers, distributors, creditors, technology providers, regulatory agencies, complementary product manufacturers, outsourcing companies, competitors and customers. NGOs, multilateral agencies, media, academics, investors, employees and government agencies complete this business ecosystem (Prahalad, 2010). Business networks are formed in such ecosystems with the eventual objective of gaining synergy. Thus, business networks help to gain agility, ensure speed of response to external events, and adapt to shift in business models in a coordinated fashion. A keystone organization is one that aims to enhance the overall health of the business network by sharing value, i.e. by contributing to business and synergy. Thus, each business firm should strive to be a keystone organization that shares value, and not become a dominant one or hublandlord that drains value (Iansiti, and Levien, 2004b). Hub-landlord organizations create friction instead of synergy, by adverse interference with the process of development and growth of other organizations and individuals in the same system, e.g., loan sharks fleecing the poor. Keystone business organizations can contribute to the development of indigenous communities by giving a fair share of their revenues, in return for indigenous knowledge about medicine, cosmetics and food (WBCSD, 2010). In such networked relationships, businesses should learn to give up control and direct influence (Prahalad, 2010). However, keystone organizations should contribute to the framework, intellectual direction, knowledge, governance, processes and standards, finance as well as technology in the context of SD. They will be enabled to play this role by making psychological contracts in business networks work, apart from legal contracts.

Nature provides us models for ensuring high performance teams (Thomson, 2008). Such teams in business ensure openness, trust, facilitate communication among team members and build a shared understanding of the goals and means. They also ensure sharing of glory among team members. Such teams, called bioteams, are different from traditional command and control teams.

Businesses should move towards a process/value chain view, instead of an intra and inter-organization structural view (vertical silos). Such networking and synergy in business should be broadened to include the context of SD. One of the futuristic models of business is a network of integrated small businesses as opposed to large monolithic businesses. 
Currently, in the context of sustainability, there exist islands of excellence in a sea of deprivation characterized by social malice, ecological degradation and economic inequity. Current unsustainable business practices, especially social and ecological, are systemic problems. The problem of unsustainability is partly due to poor communication between various interconnected and interdependent facets (Wilbanks et al, 2007). Networking and synergy would lead to flow of experiences and expertise from the islands of excellence to make sustainability global (RIMISP, 2009). For this, businesses should promote close cooperation, shared values and shared vision among stakeholders towards SD (Senge, 2010).Dialogue-based relationships among the actors contribute to strengthening values like sympathy and empathy, and contribute to knowledge and innovation as productive forces (Zsolnai and Ims, 2006). Application of this principle would, among other things, facilitate feedback about the product and future trends in the customer, investor and employee market (DeSimone andPopoff, 2000; Dirk et al, 2004). Such an approach among units of the organization, supply chain and society/NGOs, as well as with Governments, would create an enabling business network to help formulate appropriate strategies and policies for SD (Dirk et al, 2004; CERES, 2011). Several business networks, such as the World Business Council for Sustainable Development, exist for dissemination of best SD practices. Such networks bring value to all partners in terms of:

- Enabling a global perspective to SD of business.

- Ensuring legitimacy in the eyes of governments and international organizations.

- Providing linkages between small, medium and large businesses globally.

- Serving to reach opinion leaders at national and international levels.

- Helping businesses with legitimacy to obtain licenses to operate in local communities.

- Enabling validation of SD messages locally.

- Helping diffusion of knowledge and ensuring advocacy for SD.

- Offering best practices and case studies in the context of SD from around the world.

- Providing access to tools and capacity building materials in the context of SD.

A business organization should be designed with the whole system in mind. This would apply even if parts of the business are sub-optimal. Businesses should extend the Darwin's concept of 'survival of the fittest' paradigm to one of survival of the 'wholest' for SD of business. This would translate into developing businesses whose self interest will be eventually subordinated to the business systems' interest, and even beyond to include society and other forms of life also. By ignoring our dependency on other forms of life, and our close partnerships with them, we have contributed to the creation of a master-slave role, which leads to the alienation of humans from themselves (Naess, 1989).

ICT technologies could help to meet the demand for synergy in such a business system through networking. Companies like ITC have used the power of the internet to connect remote locations, including villages, under the e-choupal (e-market place) initiative. Such business MT system initiatives have helped farmers to get latest updates of both, the spot and future prices of agricultural commodities in real time. This has empowered farmers to obtain the best deals for their produce. Thus businesses should use latest networking technologies for 'anyone to anyone', 'anywhere to anywhere', to 
promote synergy and connect remote communities. This is especially useful when such interconnections promote sustainability in business and economic systems. Further, businesses should leverage the power of social media and virtual communities for SD. Businesses should also leverage the network effect (benefit of being part of a value adding network) through open source software and digital ecosystems.

A few examples of the application of the principle of Ensure Synergy through Networking, in the context of SD, are given after Table 2. The analogy between ecosystems and business systems with reference to the principle of Ensure Synergythrough Networking is summarized in Table 2. Improvement of the strength and connectivity of networks, both in business SE and MT systems is the main theme in the table.

Table 2 Analogy for Principle C2: Ensure Synergy through Networking

\section{Sub-Principles for Ecosystems Sustainability}

a) Symbionts and keystones have a higher odds of flourishing compared to hyper parasites or hub landlords.

b)Integrated existence through networking, with minimization of friction, is necessary for synergy.

c) Everything has a living, flowing connection with everything else and there are no isolated entities.

d) Fitness of one species clearly depends upon the fitness of another, viz., co-evolution.

\section{Sub-Principles for SD of Business}

\section{Business SE systems}

a) Strive to be a keystone organization that shares value, and not become a dominant one or hub-landlord that drains value.

b) Make psychological contracts in business networks work, apart from legal contracts.

c) Move towards a process/value chain view, instead of an intra and inter-organization structural view.

d) Promote close cooperation, shared values and shared vision among stakeholders towards SD.

e) Extend the 'survival of the fittest' paradigm to one of survival of the 'wholest'.

\section{Business MT systems}

a) Use latest networking technologies for 'anyone to anyone', 'anywhere to anywhere', to promote synergy and connect remote communities.

b)Leverage the power of social media and virtual communities for SD.

c) Leverage the network effect through open source software and digital ecosystems.

The efforts of the Bosch-Siemens Hausgerate Group (BSHG) in 1994, is an example of 360-degree synergy through networking in practice (Chandrashekar et al, 1999). BSHG aims at being a leader in ecological practices. Key interactions outside and inside the group of companies in the BSHG program on ecological performance include the following:

a) A policy of proactively setting standards higher than German/European law on ecological performance.

b) Design, right from the start, products for better recycling and lesser pollution.

c) Improving the standards of ecological performance of suppliers through ecological criteria for selection, training on best ecological practices, ecological audits and incentive schemes.

d) Informing customers through annual ecological reports and instructions on ecofriendly usage of products. 
e) Involving dealers in 'taking back' used appliances, including those from other manufacturers.

f) Capitalizing on spare capacity in trucks used for appliance delivery - especially in taking back old appliances.

g) Customer service personnel reuse old parts or safely dispose them.

h) Eco-friendly transport consisting of $70 \%$ by rail and the remaining by road; and use of trucks with lower emissions in road transport.

i) Pervasiveness of ecological practices in all aspects of the company, viz., segregation of office waste, use of eco-friendly substances in office heating, use of packing materials to make plastic bags, and use of recycled paper to close the materials loop.

j) Employee involvement in achieving goals on ecological performance: improves motivation and qualification of employees in this area; managers become responsible for ecological goals at all levels; incentives are based on ecological performance.

k) Disposal subcontractors are used to safely dispose products.

This is an example of the sub-principles (b), (c) and (d) of business SE systems in Table 2.

Another example of this principle is that even competing businesses such as Ford, Chrysler and GM have entered into synergetic recycling partnerships (Benyus, 1997). For this purpose, they collaborate through trade associations, virtual firms, etc., and create common labeling standards for materials and components. This is an example of sub-principles (b), (d), and (e) of business SE systems in Table 2.

The European Union funded Digital Business Ecosystem is yet another example of networking and synergy in practice in business MT systems (Nachira, 2002). In such an ecosystem, software in the form of lines of code, components, applications, services, knowledge, business models, training modules, conceptual frameworks, laws, etc., are shared over the internet across small and medium enterprises. If done early, this network enables SMEs to face up to competition from large enterprises and even provide competitive advantage. This is an example of sub-principle (c) of business MT systems and (e) of business SE systems in Table 2.

Cemex, a building materials producer is involved in a partnership with the government, universities, NGOs and private land owners. The objective of this effort is to protect and enhance the trans-boundary ecosystem in the El Carmen-Big Bend region on the US and Mexico border. This initiative includes inputs of scientific research and proven wildlife management practices. The accomplishment of this initiative was not only to reverse the biodiversity loss due to logging, grazing and mining, but also to reintroduce the locally extinct species. This accomplishment would not have been possible without the partners' strategic guidance and improved understanding of biodiversity. It also helped the company build strong relationships with the partners associated in this initiative. This is an example of the sub-principles (a), (b), (d) and (e) of business SE systems in Table 2.

While the principle of Ensure Synergy through Networking deals with connectedness and functional integration, the principle of appropriate controls, discussed in the next section, deals with ensuring effective dynamics in the network.

\section{Principle C3: Adopt Appropriate Controls}


Control in a system is its ability to purposefully facilitate change in the desired direction. Hence, control is a key dynamic property of connectedness.

In the context of sustainability, controls are in-built in ecosystems, as in the following examples:

a) Polar bears hibernating and birds migrating in winter are in-built biological controls to enable the respective species to adapt to and minimize energy losses or avoid stresses in winter.

b) Decline of a predator species following decline of their prey is a well known example of the dynamic balance between the corresponding species populations and of natural population control among the species. For example, sea otter (predator) and sea urchin (prey) populations are dynamically controlled through their predator-prey relationships.

c) The regulation of body temperature within a small range in all warm blooded animals, irrespective of huge variations in their natural environmental temperature, which may continue over extended periods of time is another example. This enables the survival of these animals even under adverse conditions.

d) The navigation of a flock of geese migrating over long distances, characterized by its timing, direction and speed, is controlled by the leader and the population. In the flock of geese, if the leading goose tires out another member automatically takes the lead, an example of control through self-organization (Senge, 2010).

e) Fire resistant barks or fire induced bursting of pods to release seeds serve as control measures in the context of forest/grassland fires to ensure species survival, through protection and propagation/reproduction, respectively (Scale, 2010).

From these examples, it is evident that self-organization, self-regulation, and selfhealing are primary control mechanisms in ecosystems (Gorshkov et al, 1999;Peltoniemi and Vuori, 2004).

In ecosystems, control varies spatially, temporally and/or contextually, or in a combination, as appropriate. Contextually, there are two theories of control in ecosystems, viz., bottom-up and top-down. The bottom-up control theory states that it is the nutrient supply available in the form of primary producers (amoeba and plants) that controls the functioning of an ecosystem. The top-down theory states that it is the predation and grazing by higher tropic species on lower species that ultimately controls an ecosystem's sustainability. Studies indicate that both controls operate simultaneously, with bottom-up control being stronger at the lower levels and top-down control being stronger at the higher levels of the species in the food chain of an ecosystem. Thus, context-driven, natural control mechanisms enable inter- and intra-species balance, and the balance in the abiotic environment (Gorshkov et al, 1999). Contextual controls include endogenous interactions, in which control information flows through the growing structure, for example, in the form of hormones, nutrients, or water; and exogenous interactions, in which control information flows through the environment such as shading, crowding, competition, etc., (Przemyslaw, 1998). Migration of birds is an example of spatial and temporal control mechanisms in operation. Here, the endogenous program responds to specific seasonal needs, with more time invested in storing fuel for a safe journey in autumn and more time invested in flying to reach the breeding grounds early in spring (Magginiand Bairlein, 2010). 
In ecosystems, signaling is an important aspect of controls. The species that are surrounded by, depend upon, and/or interact with one another through links, have the ability to send control information. This is in the form of unambiguous signals to communicate their intentions in order to gain a minimal or subsistence level of control in a given situation. For instance, several animals when defeated in a fight within the same species, either for territory or for mates, signal their submission (control information) distinctively in order to avoid unnecessary waste of energy and loss of life. Likewise, successful body design and behaviour in species are high on control information and reverberate through the whole system as signals (Benyus, 1997).Aposematic signals ${ }^{1}$ in ecosystems are examples wherein organisms advertise their desirability or undesirability of an encounter via either bright colouration (in the case of peacocks, ladybugs, frogs and spiders), or by conspicuous stripes (as in the case of the skunk) (MacAuslane, 2008). Bright colours of flowers that attract bees for pollination are an example of aposematism used to attract pollinators.

Just like ecosystems, business systems also have and need to use control mechanisms. In conventional business practices, control is a managerial function to check and minimize errors and to take proactive or reactive corrective actions. This is to overcome deviations from standards and/or stated goals, often dictated from above. The analysis of budgets versus actuals in the context of business finance and exception handling procedures in the context of business administration are examples of control in current business SE systems. Statistical process control in quality systems, so that they operate at full potential to produce quality-conforming products, is an example of control of business MT systems. Conventional efficiency based, incentive driven control strategies are appropriate for technology based business and industrial systems. Such strategies interpret control as the influence exerted by higher elements in a business system hierarchy on the lower elements or subordinates to seek their compliance with organizational goals, often set by the higher management.

In business, four characteristic control modes are prevalent. They are: (a) scrambled, (b) opportunistic, (c) tactical, and (d) strategic (Hollnagel and Woods, 2005). In the scrambled control mode, the choice is basically random. In the opportunistic control mode, the salient features of the current context determine the next action. In the tactical control mode, performance follows a known and articulated procedure or rule. In the strategic control mode, the time horizon is wider and goals are at a higher level.

These control strategies also have a parallel in the Business Process Maturity Models (BPMM), discussed in literature. According to these models, maturity of control in a business can be identified at five ordered levels, as given below:

Level 0 - Non-Existent: No management practice to achieve desired results.

\footnotetext{
${ }^{1}$ Aposematic signals are primarily visual and involve bright and contrasting colours. They may be accompanied by one or more signals other than colour. These may be specific odours, sounds or behaviour. Together, the predator encounters a multi-modal signal from potential prey, which is even more effectively detected.
} 
Level 1 - Initial level (Chaos): There is no documented management system, and 'crisis management' (or, 'firefighting') prevails. A few managers attempt to apply processes and controls to obtain desired results.

Level 2 - Managed level: 'Managers' are employed and the organization is managed on an ad hoc basis. Duties may be delegated.

Level 3 - Planned level: Organizational activities are planned, and a documented management system may be introduced (e.g., Quality Management System). But, no companywide standards or enforcement exists.

Level 4 - Integrated level: An integrated management system is implemented to manage critical risk areas (quality, safety, environment, security). Appropriate administrative risk control is implemented for all risk areas. Practices are standardized and outcomes are monitored.

Level 5 - Optimized level: Administrative risk controls are subject to continual improvement, making the organization responsive to its external and internal environments. Development is sustainable under strategic control in the context of business SD.

An organization's climb up the maturity levels is often accomplished by parallel change in control from scrambled to strategic and top down to adaptive self-control. From the above examples, it can be observed that organizations should avoid scrambled (random) and opportunistic (situation based) modes of control; and adopt tactical (rule based) and strategic (long-term goal based) control.

A key pre-requisite for a business system's ability to maintain a healthy state, or to transition from an unhealthy to healthy state, is to re-organize/re-adjust its boundaries and/or re-align/change both in the scope and the types of business controls used (Sundströmand Hollnagel, 2006). Proctor and Gamble has been able to successfully implement sustainability-oriented strategies by addition of a combination of both formal and informal controls as well as coordination across business units and decentralized structures (Riccaboni and Leone, 2010).

Experimental and trial and error changes in control are essential in complex, dynamically changing, discontinuous business environments (typically in the back loop of the Panarchy model (self-reference). The new control paradigm acknowledges that human involvement increases as one moves along the continuum of data, information and knowledge in such complex systems (Malhotra, 2001). Here, as in ecosystems, selfadaptive systems are appropriate for transformational changes in the context of SD. Internal motivation is the hallmark of self-regulation and self-control and is fundamental to converting information into action in self-adaptive systems. This opens up a large repertoire of appropriate responses and actions towards desired goals. This adaptive, self-control strategy also opens up a large variety of solutions to problems on the basis of imagination, analysis, experiment and criticism across all levels of organizations, instead of being handed down from above. Such self-adaptive control is facilitated by clear and constant encouragement, support and communication by the senior management in organizations.

During transition periods, appropriate change management teams and mechanisms need to be in place to ensure successful transition towards sustainability. The Mundragoncorporation is an example of a large business, which operates on the 
principle of self-regulation and self-control. Started in 1956, with just five employees in Basque, Spain, the cooperative corporation has grown to become the largest in Basque and seventh largest in Spain, competing internationally in the areas of finance, industry, distribution and knowledge. The employees of the organization, based on the information of the negative impact of the recent global economic slowdown on the organization, acted in a self-adaptive way by voluntarily taking a cut in salary as well as reduced working hours, as a way of tiding over difficult times.

Thus, we can compare the characteristics of top-down control and adaptive self-control in business (Malhotra, 2001) as summarized below in Table 3.

Table 3: A Comparison of Characteristics of Control Strategies in Business

\begin{tabular}{|l|l|}
\hline \multicolumn{1}{|c|}{ Top-Down Control } & \multicolumn{1}{c|}{ Adaptive Self-Control } \\
\hline Use of knowledge is the antecedent. & Self-control is the antecedent. \\
\hline External control is a consequent. & Knowledge creation is a consequent. \\
\hline $\begin{array}{l}\text { Appropriate when the environment is stable } \\
\text { typically in the fore loop Panarchy model). }\end{array}$ & $\begin{array}{l}\text { Appropriate when the environment is } \\
\text { complex, dynamic and discontinuous } \\
\text { (typically in the back loop of the Panarchy } \\
\text { model). }\end{array}$ \\
\hline Changes are incremental. & Incrementally continuous pace of change. \\
\hline $\begin{array}{l}\text { Nature of change is continuous and } \\
\text { predictable. }\end{array}$ & $\begin{array}{l}\text { Nature of change is discontinuous and } \\
\text { unpredictable. }\end{array}$ \\
\hline Single loop learning. & Double loop learning and self-adaptation. \\
\hline $\begin{array}{l}\text { Static knowledge: rules, procedures and } \\
\text { policies. }\end{array}$ & Dynamic view of knowledge. \\
\hline Knowledge resides with management. & More equitable distribution of knowledge. \\
\hline $\begin{array}{l}\text { Lower level jobs relieved of complexity of } \\
\text { initiatives. }\end{array}$ & Complexity is handled at all levels. \\
\hline
\end{tabular}

Controls should be tailored in the context of SD of business and manifest across the economic system level to the individual level. At the economic system level, one of the major issues in the context of SD is existence of market failure due to externalities and public goods. Efficiency improvements and waste reduction should align with business goals. For this, businesses should internalise externalities and price resources and pollution properly (WBCSD, 2000; McDonough and Braungart, 2002). Thus, apart from laws and fiscal incentives, self-regulation and appropriate markets for carbon and biodiversity are required as control measures towards SD at the economic system level. Walt Disney's Celebrations in Florida is an example of internalizing externalities towards SD in a land development project (Stringham et al., 2010).

In the context of long-term sustainability at the business firm level, there is a need to use preventive strategies and adopt precautionary principles $(\mathrm{PP})$, before introducing new technologies/products (Dirk et al, 2004). PP is especially relevant when firms wish to deploy novel technologies or perform activities that may expose people and/or the planet to adverse risk. While there are many versions and interpretations of the PP, Stewart (2002) reduced it to four basic versions as given below, ranging from the weakest to the strongest: 
1. Non-Preclusion PP: Regulation should be imposed on activities that pose a potential risk of significant harm even if scientific uncertainty prevails about the harm and its extent.

2. Margin of Safety PP: Activities should be limited below the level, with a margin of safety, at which no adverse effect has been observed or predicted.

3. BAT PP: When an activity must be performed despite its harmful consequences, the best available technology (BAT) must be used to minimize the risk of harm due to the said activity.

4. Probibitory PP: Activities that present an uncertain potential for significant harm must be prohibited unless the proponents of the activity show that it presents no significant risk of harm.

There is need to transition from weak to strong 2 PP. Dresner (2002) concludes that in the current context of sustainability challenges, anything less than strong PP would not guarantee future generations' ability to maintain their welfare in a worst-case outcome, under uncertainties. The Body Shop International, a UK-based cosmetics company, used Non Preclusion PP in their beauty care products in 2006 (Innovest, 2007). PP is also reflected in governments' requirements of the drug industry to prove beyond any doubt that no possible harm can occur because of any drug being introduced in the market. However, in connection with any sustainability initiative (e.g., dealing with global warming, ozone depletion, biodiversity loss, genetic pollution, etc.), the burden of proof that it is much more likely to be safe than dangerous has conventionally belonged to those who sought to minimize risk (Dresner, 2002). Proactive pollution prevention is not only a control strategy but also helps to save money and secure health as demonstrated in many cases (US EPA, 2011).

Business should ensure mechanisms for public disclosure about performance on the social and ecological bottom line. These could include disclosure about environmental, health and safety hazards of operations and products, as well as assessment, audit and compensation for damages. This would ensure adequate and appropriate control in the system towards SD (CERES, 2011). Many gas line companies have resorted to disclosure to stakeholders about the possible environmental hazards of the fracture extraction technique used in gas fields. This has enabled the public to monitor the effects of gas exploration on ground water and other natural resources (Lewis, 2011). A priori public disclosure regarding large-scale public projects is a powerful example of all four versions of PP, depending upon the nature of the disclosure and the respective project. Likewise, even a posteriori public disclosures contribute to control mechanisms, although not using PP.

In the context of business SE systems, constant monitoring of ecological and socioinstitutional processes is critical in the wake of dynamically evolving phenomena like SD (Tschakert and Dietrich, 2010). In the context of business MT systems, businesses

2 Strong PP precludes what could be harmful actions, even if the economic costs are high, unless the proponents prove beyond any doubt the harmlessness of the action. Weak PP involves a cost-benefit analysis and action is controlled only if the damage could be severe and irreversible. 
should strengthen analytical methodologies for enabling continuous, real-time, in-process monitoring and self-control prior to the formation of hazardous substances, waste resources and other SD parameters (Anastas and Warner, 1998). Businesses should measure and act on leading and lagging indicators of health under the triple bottom line and monitor the social and ecological environment (Hanson et al, 2010). Such feedback links should exist with the external environment (equivalent to exogenous control in nature) as well as within businesses (equivalent to endogenous control in nature) (Benyus, 1997).

Business controls are typically oriented to monitoring and acting on short-term phenomena like next quarter's profits or the next government policy change in tax breaks. However, SD is typically a long-term phenomenon. Hence, controls relating to SD need to be oriented to monitoring and acting on long-term phenomena (especially in case of slow variables discussed in systems thinking literature) (Meadows, 1997).

Van Zeijl-Rozema and Martens (2010) have concluded that sustainability indicators have to be composite and adapted to the region and business in the context of SD. These indicators would serve their purpose if the act of measurement triggers corrective action, during windows of opportunities. This often exists during discontinuities (the back loop of the Panarchy model), as in the current crises in the context of SD. Corrective actions can be facilitated by incentivizing managers and employees on the triple bottom-line as a control strategy (WBCSD, 2010), among others. This is different from the conventional emphasis on growth and profitability alone as key indicators or adopting top-down control strategies.

Many tools and indicators are available to guide companies to implement eco-efficiency practices, measure eco-efficiency and report performance (WBCSD, 2000). Such indicators may be market or non-market. The market indicators include eco-efficiency ratios (ratio of value indicator to environmental impact), percentage of business and growth of business from green/responsibly sourced products, brand loyalty, innovation, workforce satisfaction, etc. Non-market indicators such as cost savings from Green/CSR initiatives, as well as companies' influence on opinion leaders, and other influential individuals, sections and institutions of society should also be included (Schaltegger, 2010).Similarly, indicators of impact on society and ecology (in the external environment) must also be developed. An example is Biological Quality Indicator (BQI) of landfill sites of businesses (Knoepp, 2000). Further, the amount of greenhouse gases sequestered by afforestation or the carbon footprint over the entire lifecycle need to be measured (WBCSD, 2009 and 2010). 'Ecological balance sheets', apart from traditional financial balance sheets, should be prepared and used (Rowledge et al, 1999). The influence of socio-cultural, political, and legal institutions must also be measured (Schaltegger, 2010).

Appropriate structures and processes are critical to ensure sustainability. The involvement of departments of sustainability management,strategic planning, accounting, management control, market research, marketing, production management, R\&D, human resources, knowledge management, public relations and others should be ensured (Schaltegger, 2010). For this purpose, businesses need to embed responsibility for SD in each department/division, along with a corporate executive for sustainability. Further, 
governance mechanisms with external stakeholders, and two-way communication and dialogue would also facilitate SD in business.

Empowerment of employees to draw on their own creative forces towards sustainable business, rather than they being treated as shirkers of responsibility to be brought and kept under control, is an example of control based on self-organizational structure and process (Nelson, 2006). Natural biota represents a unique ultra-complex mechanism responsible for developing and maintaining earth's habitability and its ecosystem services. In order to ensure the long-term sustainability of favorable environmental conditions, the modern business should facilitate natural biotic regulation mechanisms to continue to operate on earth to ensure SD of business (Gorshkov et al, 2004).

A few examples of the application of the principle of Adopt Appropriate Control, in the context of SD, are given after Table 4. The analogy between ecosystems and business systems with reference to the principle of Adopt Appropriate Controls is summarized in Table 4. Business should use internally driven, adaptive control based on experimentation and limit the use of top-down control or efficiency-based, incentive driven control, which is fundamental to transition towards SD of business, as summarized in the table.

\section{Table 4: Analogy for Principle C3: Adopt Appropriate Controls}

\section{Sub-Principles for Ecosystems Sustainability}

a) Self-organization, self-regulation, and self-healing are primary control mechanisms.

b) Control varies spatially, temporally and/or contextually, or in a combination.

c) Bottom-up and top-down controls operate simultaneously; bottom-up is stronger at the lower levels of the ecosystem, while top-down is stronger at the higher levels.

d) Control is exogenous or endogenous, depending upon the circumstances.

e) Species send control information in the form of unambiguous signals to communicate intentions in a given situation.

\section{Sub-Principles for SD of Business}

\section{Business SE Systems}

a) Avoid scrambled (random) and opportunistic (situation-based) modes of control; ensure tactical (rule-based) and strategic (long term goal-based) control.

b) Internalize externalities, price resources and pollution properly.

c) Ensure mechanisms for public disclosure about performance on the social and ecological bottom line.

d) Measure and act on leading and lagging indicators of business health under triple bottom line; monitor the social and ecological environment.

e) Embed responsibility for SD in each department/division, along with a corporate executive for sustainability.

f) Facilitate natural biotic regulation mechanisms to continue to operate.

g) Use internally driven, adaptive control based on experimentation; limit use of top-down control or efficiency-based, incentive driven control.

\section{Business MT Systems}

a) Use preventive strategies and adopt precautionary principles (PP), before introducing new technologies/products.

b) Transition from weak to strong PP.

c) Strengthen analytical methodologies for enabling continuous, real-time, inprocess monitoring and selfcontrol prior to the formation of hazardous substances, waste resources and other SD parameters.

Swiss Re and other European insurance companies have used the sub-principles of (a) in MT systems and (d) in SE systems in table 4, in relation to climate change (Lovins et 
al, 1999). The long-term effects of global warming on insurance claims have been responsible for this strategy. They have pioneered efforts to mitigate climate change, among the business community and other stakeholders. This is an example of temporal and contextual control.

Georgia Power Company initially used manual controls to supervise the performance of their production processes (Lovins et al, 1999). This was until they started using microprocessor-based controls designed by fresh graduates out of college. Soon, these graduates were pioneering a transformational initiative across the company to optimize and improve controls throughout the production processes in the context of SD. This is an example of contextual control in MT systems, and is an illustration of the subprinciple (c) of business MT systems in table 4.

Perfluorocarbons (PFCs) is a high global warming potential greenhouse gas produced during aluminium production, due to poor control of flow of aluminium oxide to the anode. These emissions can be significantly reduced by careful attention to operating procedures and more use of computer-control. The industry had committed to $80 \%$ reduction of PFCs by 2010, compared to the level of 1990. Latest data indicates that this target was exceeded in 2006 itself (IAI, 2008). This is an example of temporal and contextual control in an MT system, and is an illustration of the sub-principle (c) of MT systems in table 4.

Of the Unilever's greenhouse gas emissions in the value chain of the food business, $50 \%$ emanate from the raw materials in their supply chain from agriculture. Unilever has developed a greenhouse gas calculator, a tool for measuring site specific greenhouse gas emissions and help farmers assess mitigation options. This is implemented with the help of a consortium of industries, NGOs, academics and labs. This tool helps the Government and the company to identify barriers to mitigate climate change caused by agriculture and overcome them (WBCSD, 2009). This is an example of spatial control and the sub-principles (d) and (f) of business SE systems and (c) of business MT systems in Table 4.

It is evident from the above examples that the most effective control in the context of $\mathrm{SD}$, is self-adaptive control. While a particular principle may operate primarily in the dimension of Connectedness discussed above, it may also have a second order spill over effect on the other dimensions of the Panarchy model.

\section{Conclusion}

It can be observed that the analogies between ecosystems and business SE and MT systems are indeed strong in the context of SD on this dimension of Connectedness in the Panarchy model. Further, these analogies are triangulated with principles of financial sustainability and current business literature. It is evident that the dimension of connectedness is an important dimension of SD of business. 
Future research in this area could include empirical validation of the scale of SD of business on the dimension of Connectedness, based on these principles and subprinciples. Further, development of a systems dynamic model or a regression equation on this can be attempted.

The survivors in ecosystems are those species that meet their needs without compromising the survival of their and others' offspring, even ten thousand generations from now (Benyus, 1997; Lovins et al, 1999). Lack of social/ecological sustainability in business organisations entails the risk of modern business organisations becoming the dinosaurs of tomorrow. Modern businesses may then be replaced by more sustainable forms of organizations that meet society's materialistic needs, if this occurs. These Principles of SD of Business derived in the dimension of Connectedness along with the other two dimensions of Potential and resilience are required for SD of business to be operational.

\section{References}

Anastas, P.T. and J.C. Warner(1998) Green Chemistry: Theory and Practice, Oxford University Press: New York, p.30.

Benyus, J. M.(1997) Biomimicry: Innovation Inspired by Nature, Harper Collins, New York.

CERES(2011) CERES Principles.Downloaded from http://www.iisd.org/business/tools/principles_ceres.aspxCeres (investors and environmentalists for sustainable prosperity).

Chandrashekar, A., T. Douglessand C. Gayle (1999) The Environment is Free: The Quality Analogy. Journal of Quality Management, 4 (1), 123-143.

Daly, H.E. and J. Cobb(1989) For the Common Good: Redirecting the Economy toward Community, the Environment and a Sustainable Future. The Beacon Press, Boston.

DeSimone, L. D. andF. Popoff(2000) Eco-Efficiency: The Business Link to Sustainable Development. MIT Press, Cambridge.

Dirk, J., S Hausmann, C. Liedtke and E. U. Weizsäcker (2004) Eco Efficiency and Beyond Towards the Sustainable Enterprise, Green Leaf Publishing, Sheffield, UK.

Drake, D. C., B.J. Peterson, K.A. Galva, L.A. Deegan, C. Hopkinson, J.M. Johnson, K. K. Jakobsen, L.E. Lemay and C. Picard “, (2009) Salt Marsh Ecosystem Biogeochemical Responses to Nutrient Enrichment: A Paired 15N Tracer Study. Ecology,90 (9), 25352546. Downloaded from https://darchive.mblwhoilibrary.org/bitstream/handle/1912/2984/Drake\%20et\%20al $\% 20$ Ecology $\% 202009$.pdf?sequence $=1$.

Dresner, S. (2002) The Principles of Sustainability, Earthscan, London.

Elkington, J. (1998) Cannibals with Forks: The Triple Bottom Line of 21st Century Business, Oxford University Press, London, 1998.

Fish, F.E. (2006) Limits of Nature and Advances of Technology: What does Biomimetics have to Offer to Aquatic Robots? ABBl, 3(1),4940-4960.Down loaded from citeseerx.ist.psu.edu/viewdoc/download?doi=10.1.1.103.

Gorshkov, V.V., V.G. Gorshkov, V.I. Danilov-Danil'yan, K.S. Losev, and A.M. Makar'eva (1999) Biotic Control of the Environment, Russian Journal of Ecology, 30(2), 87-96. Translated from Ekologiya, No. 2, 105-115. 
Gunderson, L. H., and C. S. Holling(2002) Panarchy: understanding transformations in human and natural systems. Island Press, Washington D.C.

Hanson, C., J. Ranganathan, C. IcelandandJ.Finisdore (2010) The Corporate Ecosystem Services Review - Guidelines for Identifying Business Risks and Opportunities Arising from Ecosystem Change, Downloaded from http://pdf.wri.org/corporate_ecosystem_services_review.pdf.

Hollnagel, E. and Woods, D.D. (2005) Joint cognitive systems: Foundations of cognitive systems engineering.: Taylor \& Francis / CRC Press, Boca Raton, FL, 2005.

Hollnagel, E., D.D. Woods and N. LevesonResilience engineering: concepts and precepts. Ashgate Publishing, Ltd., London, 2006.

IAI (2008) The Aluminium Industry's Greenhouse Gas Mitigation Strategy. News letter Feb 2008. Downloaded from http://www.worldaluminium.org/UserFiles/File/IAI\%20Newsletter\%20February\%202008.pdf

Iansiti, M. and R. Levien(2004)The Keystone Advantage: What the New Dynamics of Business, Harvard Business School Press, Boston.

Innovest (2007) Cross Cutting Effects of Chemical Liability from Products. Down loaded from http://www.sehn.org/tccpdf/liability $\% 20$ from $\% 20$ chemicals $\% 20$ in $\% 20$ products.pdf

Jacobs, J.(2000) The Nature of Economics. Random House, New York.

Knoepp, J. D., D.C. Coleman, D.A. Crossley Jr. and J.S. Clark (2000) Biological indices of soil quality: an ecosystem case study of their use. Forest Ecology and Management, 138, 357 368.

Lerner, E.J. (2003) What's wrong with the electric grid? The Industrial Physicist, 5(9), 8-13.

Downloaded from http://www.aip.org/tip/INPHFA/vol-9/iss-5/p8.html.

Leveque, C. (ed.) (2003) Ecology: From Ecosystem to Biosphere. Science Publishers, New Hampshire.

Lewis, S. (2011)Frack! Can The Energy Giants Learn From Independent Gas

Companies? CSRwire Talkback, Apr 10. Downloaded from

http://csrwiretalkback.tumblr.com/post/4501717770/frack-can-the-energy-giantslearn-from-independent-gas.

Lovelock, J.E. Gaia, a New Look at Life on Earth. Oxford University Press: Oxford, 1979.

Lovins, A.B., L. H. Lovinsand P. Hawken(1999) Natural Capitalism - The Next Industrial Revolution.Earthscan, London.

MacAuslane, H J. Aposematism, Capinera (Ed) (2008) Encyclopedia of Entomology, Vol 4., 2008, 239-242.

Maggini, I. and F. Bairlein (2010) Endogenous Rhythms of Seasonal Migratory Body Mass Changes and Nocturnal Restlessness in Different Populations of Northern Wheatear Oenantheoenanthe.Biological Rhythms, 25(4), 268-276. Downloaded fromhttp://jbr.sagepub.com/search?author1=Ivan+Maggini\&sortspec $=$ date\&submit $=S$ ubmitand Bairlein.

Malhotra, Y. (2001) Organisational controls as Enablers and Constraints in successful knowledge Management Systems Implementation. 326-336.,Malhotra, Y. (ed.) Knowledge Management and Business Model Innovation, Idea Group Publising, Hershy, PA..

McDonough, W. and M. Braungart, (2002) Cradle to Cradle: Remaking the Way We Make Things, North Point Press, New York.

Meadows, D. H. (1997)Leverage points: Places to Intervene in the system. Sustainability Institute, Hartland.

Meadows, D., J. Randers and D. Meadows(1992) Beyond the Limits. Chelsea Green Publishing Co., Vermont.

Meadows, D., J. Randers and D. Meadows (2004) Limits to Growth: The Thirty Year Update. Chelsea Green Publishing Co., Vermont. 
Merry, U. (1999) Organizational Strategy on Different Landscapes: A New Science Approach.Systemic Practice and Action Research, 12(3), 257-278.

Mitleton-Kelly E.(2003) Complexity Research - Approaches and Methods: The LSE Complexity Group Integrated Methodology.Keskinen A, M. Aaltonen, and E. Mitleton-Kelly (eds.) Organizational Complexity. Scientific Papers 1/2003, TUTU Publications, Finland, Helsinki.

Moir, J.W.B. (ed.) (2011)Nitrogen Cycling in Bacteria: Molecular Analysis. Caister Academic Press, Noewich, UK.

Naess A., D. Rothenberg (Translator) (1989)Ecology, Community and Lifestyle. Outline of an Ecosophy. Cambridge Unviersity Press, Cambridge.

Nelson, J.(2006) The Relational Firm: A Buddhist and Feminist Analysis. 195-217. Zsolnai L. and K. J. Ims.(Eds.) Deep Ecology and Buddhist Economics. Peter Lang Publishing, Oxford.

Ohno, T.(1989) The Toyota Production System: Beyond Large Scale Production. Productivity Press, Portland, OR.

Peltoniemi M. and E. Vuori(2004)Business Ecosystem as the New Approach to Complex Adaptive Business Environments.Proc. 4th Annual Conference eBRF (eBusiness Research Forum), Tampere, FL, 267-281.

Prahalad, C. K. (2010) Fortune at the Bottom of the Pyramid, Wharton School Publishing, Harvard.

Przemyslaw, P. (1998) In Search Of The Right Abstraction: The Synergy Between Art, Science, and Information Technology in the Modeling of Natural Phenomena. 60-68.Sommerer C. and L. Mignonneau (Eds.):Art@ Science. Springer, Wienna.

Riccaboni, A. and E.L. Leone (2010) Implementing Strategies through Management Control Systems: The Case of Sustainability. International Journal of Productivity and Performance Management, 59(2), 130-144.

RIMISP (2009) Annual Report 2009.Latin American Centre for Rural Development. Downloaded from www.rimisp.org/FCKeditor/UserFiles/File/.../Annual-Report-2009.pdf

Rowledge, L., R. Barton and K. Brady(1999) Mapping the Journey-Case Studies in Strategy and Action towards Sustainable Development.Greenleaf publishing Ltd., Sheffield.

Scale (2010) Understanding Scale.Downloaded from http://www.sustainablescale.org/ConceptualFramework/UnderstandingScale/Measurin gScale/.

Schaltegger, S. (2010)Sustainability as a Driver for Corporate Economic Success- Consequences for the Development of Sustainability Management Control. Down loaded from www.leuphana.de/csm/.

Senge, P.M. (2010) The Fifth Discipline, The Art and Practice of a Learning Organization. Currency and Doubleday, New York, 2010.

Simmie, J. and R. Martin (2010) The Economic Resilience of Regions: Towards an Evolutionary Approach. Cambridge Journal of Regions, Economy and Society, 3(1), 27-43.

Stewart, R.B. (2002) Environmental Regulatory Decision Making Under Uncertainty. Research in Law and Economics, 20, 71-126.

Stiglitz, J. E., A. Sen, J. P. Fitoussi(2009)Report by the Commission on the Measurement of Economic Performance and Social Progress. Downloaded from www.stiglitz-sen-fitoussi.fr

Stringham, E.P., J. K. Miller and J.R. Clark (2010)Internalizing Externalities Through Private Zoning: The Case of Walt Disney Company's Celebration, Florida. Journal of Regional Analysis and Policy, 40(2), 96-103.

Thomson, K.(2008) Bioteams: High Performance Teams Based on Nature's Most Successful Designs.Meghan-Kiffer Press, Tampa, FL. 
Tschakert, P. and K. A. Dietrich (2010) Anticipatory Learning for Climate Change Adaptation and Resilience.Ecology and Society,15(2), 11 (online).Downloaded from http://www.ecologyandsociety.org/vol15/iss2/art11/.

US EPA (2011) Case Study 6: Pollution Prevention Beyond Regulated Materials. Down loaded in May 2011 from http://www.epa.gov/dfe/pubs/pwb/case_stu/case6/index.html

vanZeijl-Rozema, A. and P. Martens (2010) An Adaptive Indicator Framework for Monitoring Regional Sustainable Development: A Case Study of the INSURE Project in Limburg, The Netherlands. Sustainability: Science, Practice, \& Policy, 6(1). Downloaded from http://sspp.proquest.com/archives/vol6iss1/0901-004.vanzeijl.html.

Visser, W. (2005) Business Frontiers: Social Responsibility, Sustainable Development and Economic Justice.ICFAI Books, Down loaded from http://www.waynevisser.com/book_bf_chap3_holistic_business.pdf

WBCSD (2000) Eco-Efficiency: Creating More V alue with Less Impact. Downloaded from http://www.wbcsd.org/Plugins/DocSearch/details.asp?DocTypeId=25\&ObjectId=Mj c5\&URLBack $=\% 2$ Ftemplates $\% 2$ FTemplateWBCSD $\% 2$ Flayout $\% 2$ Easp $\% 3$ Ftype $\% 3 \mathrm{D}$ $\mathrm{p} \% 26 \mathrm{MenuId} \% 3 \mathrm{DODU} \% 26 \mathrm{CurPage} \% 3 \mathrm{D} 20 \% 26$ SortOrder $\% 3$ Dpubdate $\% 2520$ desc

WBCSD (2009) Tackling Climate Change on the Ground. World Business Council for Sustainable Development publication. Down loaded from wbcsd.org.

WBCSD (2010) Responding to the Biodiversity Challenge Business contributions to the Convention on Biological Diversity. World Business Council for Sustainable Development publication.

Downloaded from http://www.wbcsd.org/web/nagoya/RespondingtotheBiodiversityChallenge.pdf.

WCED(1987) Our Common Future.World Commission on Environment and Development, Oxford University Press, New Delhi.

Wilbanks, T.J., P. Romero Lankao, M. Bao, F. Berkhout, S. Cairncross, J.P. Ceron, M. Kapshe, R. Muir-Wood and R. Zapata-Marti(2007) Industry, settlement and society. Climate Change: Impacts, Adaptation and V ulnerability. Contribution of Working Group II.357-390. M.L. Parry M.L., O.F. Canziani, J.P. Palutikof, P.J. van der Linden and C.E. Hanson (Eds.), Fourth Assessment Report of the Intergovernmental Panel on Climate Change, Cambridge University Press, Cambridge, UK.

Womack, J.P. and D.T. Jones (2003) Lean Thinking: Banish W aste and Create Wealth in Your Corporation. Simon \&Schusters, New York.

Zsolnai, L. and K.J. Ims (eds.) (2006) Business within Limits: Deep Ecology and Buddhist Economics. Peter Lang, Oxford. 